\title{
Prevalence of Polypharmacy and Risks of Potentially Inappropriate Medication Use in the Older Population in a Developing Country: A Systematic Review and Meta-Analysis
}

\author{
Akshaya Srikanth Bhagavathula ${ }^{a}$ Eyob Alemayehu Gebreyohannes ${ }^{c}$ \\ Daniela Fialova ${ }^{a, b}$ \\ aDepartment of Social and Clinical Pharmacy, Faculty of Pharmacy in Hradec Králové, Charles University, \\ Hradec Králové, Czech Republic; ${ }^{b}$ Department of Geriatrics and Gerontology, 1 st Faculty of Medicine, \\ Charles University, Prague, Czech Republic; ' Division of Pharmacy, School of Allied Health, University of \\ Western Australia, Crawley, WA, Australia
}

\section{Keywords}

Polypharmacy · Potentially inappropriate medications .

Rational geriatric drug use $\cdot$ Developing countries

\begin{abstract}
Background and Aim: Polypharmacy and potentially inappropriate medication (PIM) use in older populations $(65+$ years) have not yet been investigated by meta-analyses in developing countries. This systematic literature review and meta-analysis aimed to investigate the prevalence of polypharmacy and PIM use and major risk factors associated with PIM prescribing in older adults in Ethiopia. Methods: We searched PubMed/MEDLINE, Scopus, Embase, and Google Scholar databases to identify relevant studies published between January 1990 and October 2020. Observational studies reporting the prevalence and association of risk factors with polypharmacy and PIM use in the older population were meta-analyzed. A multilevel meta-analysis was conducted to pool the prevalence estimates, and the risk of PIM
\end{abstract}

use was reported as a relative risk (RR) with a $95 \%$ confidence interval (Cl). Results: We identified by systematic literature review 404 articles. Of those, 8 studies fulfilled inclusion criteria, comprising a total sample of 2,608 participants. The overall prevalence of polypharmacy and PIM use pooled by meta-analysis in the Ethiopian older population was 33 and $37 \%$, respectively. The risk factors of PIM use were analyzed in the meta-analysis (particularly polymorbidity, polypharmacy, gender, and older age), and only older age of 65+ (RR: $1.71,95 \% \mathrm{Cl}: 1.16-2.51$ ) was significantly associated with PIM use. Conclusion: This first meta-analysis from a developing country revealed a high prevalence of polypharmacy and PIM use in the Ethiopian older population. There was no awareness about the risk of PIMs in patients with polypharmacy and polymorbidity, and older age significantly predicted PIM use. Interventions ensuring rational geriatric pharmacotherapy are essential in developing countries in order to reduce the expected burden of PIM-related geriatric morbidity, higher costs, and mortality.

(c) 2021 The Author(s)

Published by S. Karger AG, Basel karger@karger.com

www.karger.com/ger

Karger $\stackrel{\text { ' }}{=}$

BOPEN ACCESS
(C) 2021 The Author(s)

Published by S. Karger AG, Basel

This is an Open Access article licensed under the Creative Commons Attribution-NonCommercial-4.0 International License (CC BY-NC) (http://www.karger.com/Services/OpenAccessLicense), applicable to the online version of the article only. Usage and distribution for commercial purposes requires written permission.
Correspondence to:

Akshaya Srikanth Bhagavathula, akshaypharmd@gmail.com 


\section{Introduction}

Medications play a key role in the care of the older population, and medications prescribed to older adults take the highest share (30-40\%) of overall expenditure for prescribed medications across all age-groups $[1,2]$. Due to frequent polymorbidity and polypharmacy and use of potentially inappropriate medications (PIMs) are highly prevalent in the older population [3]. PIM use can adversely affect the older adults' health, functional status, and quality of life and is linked to a higher occurrence of drug-drug interactions, adverse drug events, worsening of geriatric syndromes, functional status decline, emergency hospitalizations, and even higher mortality [3-8].

Over the past 2 decades, several studies and reviews have reported the extensive use of polypharmacy and PIMs in older patients and their negative impact on the higher occurrence of adverse outcomes [9-15]. This concern has led to the development of explicit criteria for PIMs to be avoided in the older population, such as the Beers criteria [16], the Screening Tool of Older Persons' Prescriptions (STOPP), the Screening Tool to Alert to the Right Treatment [17], EU(7)-PIM list [18], and others [19, 20].

The number of people aged 65 years or older is expected to triple in the next 4 decades, with a rapid increase in developing countries [21]. A high majority (two-thirds) of the older population live in developing countries and have a high burden of noncommunicable diseases [22]. In Ethiopia, a Sub-Saharan African country, the older population has limited access to health care [23], and this fact also has a significant impact on higher chronic morbidity and early mortality of older adults. Ethiopia had an average healthy life expectancy of 64 years at birth in 2018 (men: 64.3 years and women: 68.1 years) [24]. The United Nations population division estimated that the population aged 65 years and above accounted for $3.5 \%$ of Ethiopia's total population in 2019 [24], and this proportion is expected to increase to $3.8 \%$ by 2050 . Already several studies conducted on the older population in Ethiopia reported a higher occurrence of falls $[25,26]$, depression [27], hypertension [28], higher eye care service utilization [29], patterns of extensive psychotic medications use [30], polypharmacy, and PIM use [31-38]. On the other hand, deprescribing strategies [23] and emphasis on the importance of medication safety and medication-related quality of life have also been described [39].

Until now, all available systematic literature reviews and meta-analyses on polypharmacy and PIM use in the older population have been conducted using data from developed countries, mostly from the US and Europe [9-
15]. This fact greatly limits the generalizability of existing results in developing countries. To overcome these limitations, we conducted the first systematic literature review on the prevalence of polypharmacy and PIM use in older adults in Ethiopia in order to obtain such firsthand evidence from a developing country.

\section{Methods}

\section{Search Strategy and Study Selection}

This systematic literature review and meta-analysis were performed following the Preferred Reporting Items for Systematic Reviews and Meta-analysis guidelines [40]. A Preferred Reporting Items for Systematic Reviews and Meta-analysis statement is included in online suppl. material; for all online suppl. material, see www.karger.com/doi/10.1159/000516075. The study protocol was registered with PROSPERO (CRD42019141037).

A comprehensive literature search was carried out in PubMed/ Medline, Embase, Scopus, and Google Scholar databases from the January 1990 inception to October 2020. Observational studies conducted on the older population in Ethiopia, published in English language, were searched using a combination of medical subject heading and nonmedical subject heading terms (online suppl. Table 1). Furthermore, a search of the reference lists of relevant articles and reviews was also performed to identify any potential studies.

We included studies that met the following criteria:

1. Peer reviewed research studies conducted in the older population in Ethiopia

2. Observational study design

3. Reported estimates of polypharmacy and PIM use in the older population

4. Medication use evaluated using any explicit criteria for PIMs

5. Documentation of any factors that increase the risk of PIM use in the older population in Ethiopia

Studies were excluded if they (1) did not report estimates of polypharmacy or PIM use in the older population; (2) did not assess PIM use based on published explicit criteria; (3) repeated use of the same data from another article; (4) editorials, commentaries, reviews, conference proceedings, interventional studies, nonhuman studies, and case reports were also excluded.

\section{Data Extraction and Quality Assessment}

Two researchers (ASB and EAG) independently investigated the identified studies based on their title and/or abstract and full text. The identified articles were imported into Endnote ${ }^{\mathrm{TM}}$, a literature management software of Thomas Reuters (New York, NY, USA), and evident duplicates were removed. Any disagreement was resolved by consensus, or if necessary, by discussing with the senior researcher (DF). The following characteristics of the included studies were extracted: the authors name, year of publication, study location, study design, study population, sample size, criteria for PIM use, estimates of polypharmacy and PIM use, and confounding factors. We also extracted the risk estimates such as odds ratio, hazard ratio, and risk ratio with corresponding 95\% confidence intervals (CIs) of the association between various factors and risk of PIM use.

The methodological quality of included studies was examined using the Newcastle-Ottawa Scale (NOS) [41] and graded out of 10 
Fig. 1. PRISMA diagram of the literature selection in this systematic literature review. PRISMA, preferred reporting items for systematic reviews and meta-analysis.

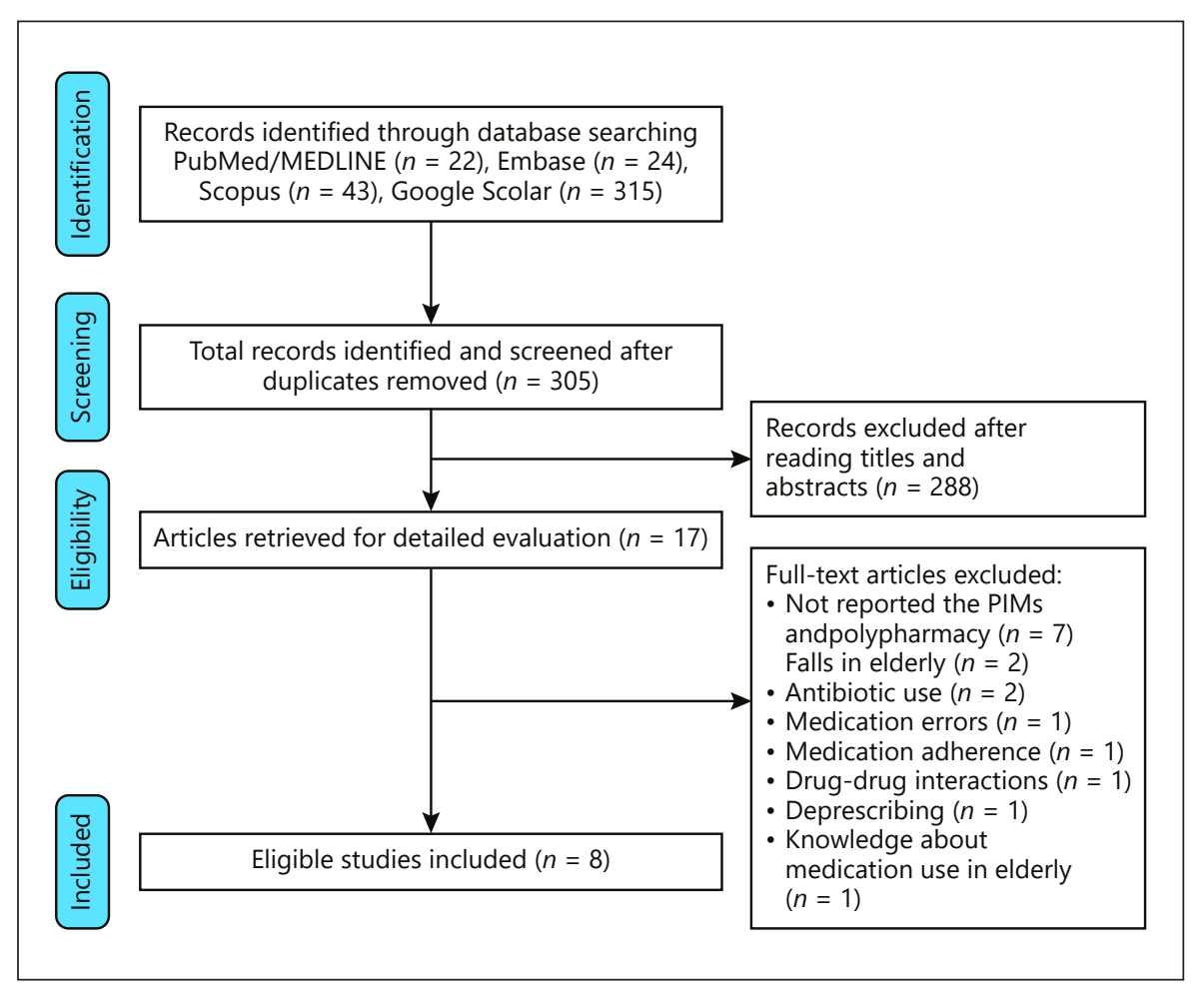

Table 1. Characteristics of included studies

\begin{tabular}{|c|c|c|c|c|c|c|c|c|c|c|c|}
\hline Author & Year & Location & $\begin{array}{l}\text { Study } \\
\text { design }\end{array}$ & $\begin{array}{l}\text { Mean age } \\
( \pm \mathrm{SD}, \\
\text { years })\end{array}$ & $\begin{array}{l}\text { Sample } \\
\text { size }\end{array}$ & Setting & $\begin{array}{l}\text { Mean } \pm \text { SD } \\
\text { of drugs } \\
\text { prescribed }\end{array}$ & PIM criteria applied & $\begin{array}{l}\text { PIM } \\
\text { prevalence }\end{array}$ & $\begin{array}{l}\text { Poly- } \\
\text { pharmacy }\end{array}$ & $\begin{array}{l}\text { Quality of } \\
\text { studies }\end{array}$ \\
\hline Tefera et al. [31] & 2020 & Gondar & $\begin{array}{l}\text { Cross- } \\
\text { sectional }\end{array}$ & - & 153 & $\begin{array}{l}\text { Inpatient and } \\
\text { outpatient }\end{array}$ & $6.44 \pm 8.04$ & - & - & $31.3 \%$ & 10 \\
\hline Abegaz et al. [32] & 2018 & Gondar & $\begin{array}{l}\text { Cross- } \\
\text { sectional }\end{array}$ & $72.5 \pm 7.7$ & 239 & Inpatient & $3.97 \pm 1.55$ & 2015 STOPP & $44.3 \%$ & - & 9 \\
\hline Yedesa et al. [33] & 2017 & Ambo & $\begin{array}{l}\text { Cross- } \\
\text { sectional }\end{array}$ & $68.4 \pm 7.26$ & 32 & $\begin{array}{l}\text { Inpatient and } \\
\text { outpatient }\end{array}$ & - & - & $87.5 \%$ & $78.1 \%$ & 8 \\
\hline Sada [34] & 2017 & Dessie & $\begin{array}{l}\text { Cross- } \\
\text { sectional }\end{array}$ & - & 244 & - & 5.1 & $\begin{array}{l}2012 \text { Beers criteria and } \\
\text { WHO core indicators }\end{array}$ & $23.1 \%$ & $23.0 \%$ & 5 \\
\hline Teka et al. [35] & 2016 & Tigray & $\begin{array}{l}\text { Cross- } \\
\text { sectional }\end{array}$ & $72.3 \pm 7.0$ & 140 & Inpatient & $5.81 \pm 2.98$ & 2012 Beers criteria & $28.5 \%$ & $28.5 \%$ & 10 \\
\hline Getachew et al. [36] & 2015 & Gondar & $\begin{array}{l}\text { Cross- } \\
\text { sectional }\end{array}$ & $71.1 \pm 6.18$ & 156 & Inpatient & $4.91 \pm 1.86$ & 2015 STOPP & $44.8 \%$ & $35.9 \%$ & 9 \\
\hline $\begin{array}{l}\text { Mekonnen and } \\
\text { Bhagavathula [37] }\end{array}$ & 2014 & Gondar & $\begin{array}{l}\text { Cross- } \\
\text { sectional }\end{array}$ & 67.8 & 1,252 & $\begin{array}{l}\text { Inpatient and } \\
\text { outpatient }\end{array}$ & - & 2012 Beers criteria & $27.7 \%$ & $6.7 \%$ & 7 \\
\hline Teni and Gedif [38] & 2014 & Gondar & $\begin{array}{l}\text { Cross- } \\
\text { sectional }\end{array}$ & $68.4 \pm 7.26$ & 392 & Outpatient & 2.3 & 2003 Beers criteria & $6.3 \%$ & - & 10 \\
\hline
\end{tabular}

SD, standard deviations; PIM, potential inappropriate medication; STOPP, screening tool of older persons' prescriptions.

points. The NOS scale examines 3 major sections: (1) methodological quality of each study (maximum of 5 points were allotted), (2) comparability of the study (2 points), and (3) outcomes with related statistical analysis ( 3 points).
Statistical Analysis

Statistical analysis was performed using STATA software, version 16 MP (StataCorp, College Station, TX, USA). Pooled prevalence was reported as percentages with $95 \% \mathrm{CI}$ and consid- 


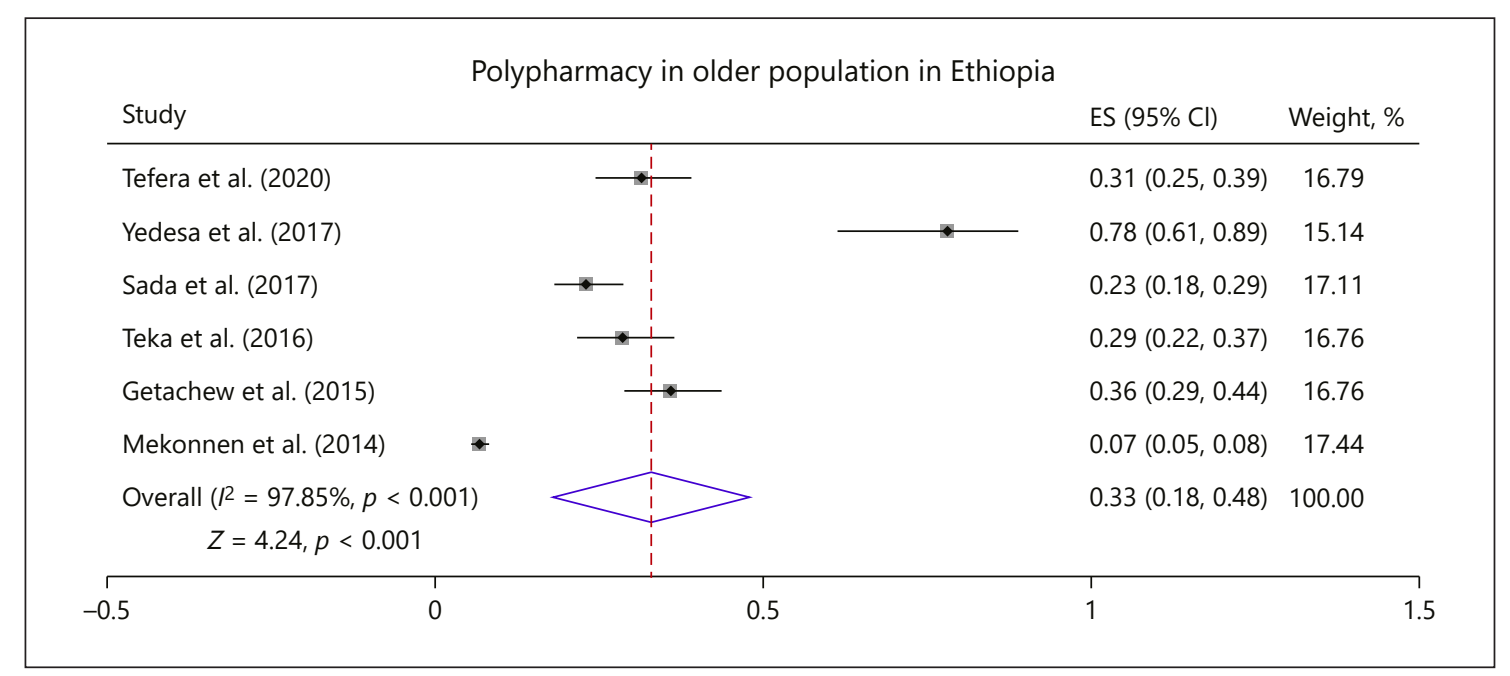

Fig. 2. Prevalence of polypharmacy in the older population in Ethiopia [31, 33-37]. CI, confidence interval.

\begin{tabular}{|l}
\hline \multicolumn{1}{|c|}{ Prevalence of PIMs irolder people in Ethiopia } \\
Study
\end{tabular}

Fig. 3. Prevalence of PIM use in older patients in Ethiopia [32-36, 38]. PIM, potentially inappropriate medication; CI, confidence interval.

ering the variations in the true effect size across the population. Der Simonian and Laird's random-effects model was applied. Pooled relative ratio was performed using its log transformation and inverse variances as weights were then calculated for each study to determine the association between various patient factors and the risk of use of PIMs. Publication bias was assessed using funnel plots for symmetry and the Egger and Begg test. Statistical heterogeneity was assessed by determining the $I^{2}$ statistic. When $I^{2}$ was $>50 \%$, heterogeneity analysis was performed by sensitivity analysis.

Polypharmacy and PIM Use in Ethiopia

\section{Results}

A total of 404 records were identified through several sources. From these, 99 duplicates were removed using Endnote. The remaining 305 records were considered to be potentially eligible for inclusion. After title and abstract screening, 288 records were excluded, and the remaining 17 full-text articles were retried and read thoroughly for further evaluation. Nine articles were excluded as the outcome of interest was found to be missing, insufficient and/ 


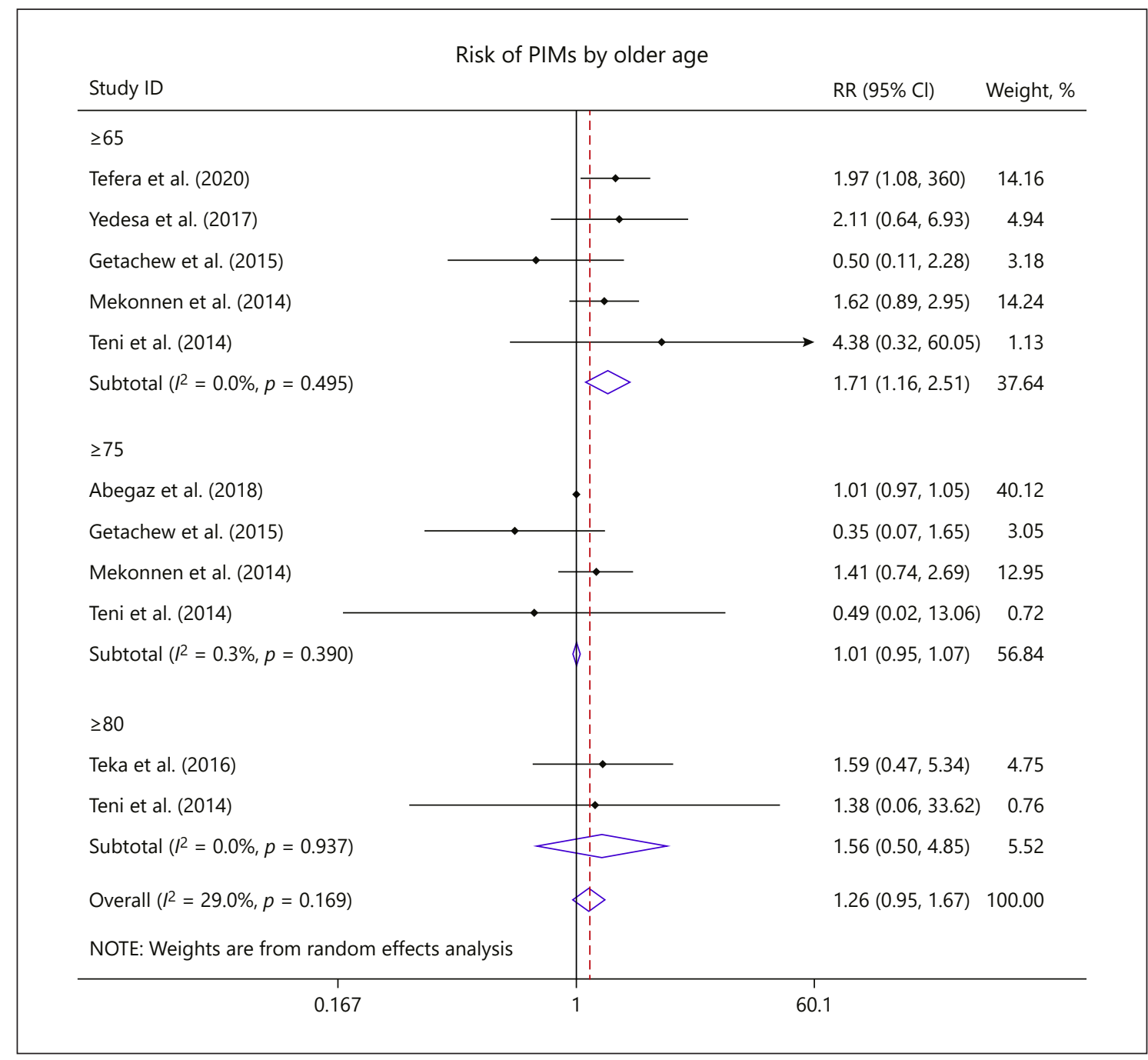

Fig. 4. Older age and risk of PIMs use ( $\geq 65$ years [31, 33, 36-38], $\geq 75$ years [32, 36-38], $\geq 80$ years [35, 38]). PIMs, potentially inappropriate medications; $\mathrm{CI}$, confidence interval; RR, relative risk.

or ambiguous (refer to online suppl. Table 2). Finally, 8 studies met the inclusion criteria and were included in the qualitative and quantitative synthesis (Fig. 1).

The characteristics of the included studies are summarized in Table 1 . These 8 studies comprising a total of 2,068 participants [31-38], representative of the elderly Ethiopian population [32-38], employing cross-sectional study design [31-38], were published from 2014 [37] to March 2020 [31] and their sample size ranged from 32 [33] to 1,252 [37]. The majority of studies were conducted in Gondar [31, 32, 36-38], and used a version of the Beers criteria (2003/2012) [34, 35, 37, 38], 2015 STOPP criteria $[32,36] ; 2$ of the studies did not specify the criteria used to identify PIM prescribing in the older popula- tion $[31,33]$. According to the NOS, the average score of studies was 8.5 , which indicates high quality, ranging from 5 to 10 (refer to online suppl. Table 3 ).

\section{Prevalence of Polypharmacy and PIM Use in the Older} Population

Six studies provided the estimates of polypharmacy in the older population; the pooled prevalence of polypharmacy in Ethiopia was found to be 33\% (95\% CI: 18-48, $p<0.001)$. The $I^{2}$ statistics revealed a high degree of heterogeneity across studies $\left(I^{2}=97.85 \%, p<0.001\right)$ (Fig. 2).

Also, the pooled prevalence of PIM use in the older population was estimated at 37\% (95\% CI: $23-51, p<$ 0.001 ). Substantial heterogeneity was present across the 7 


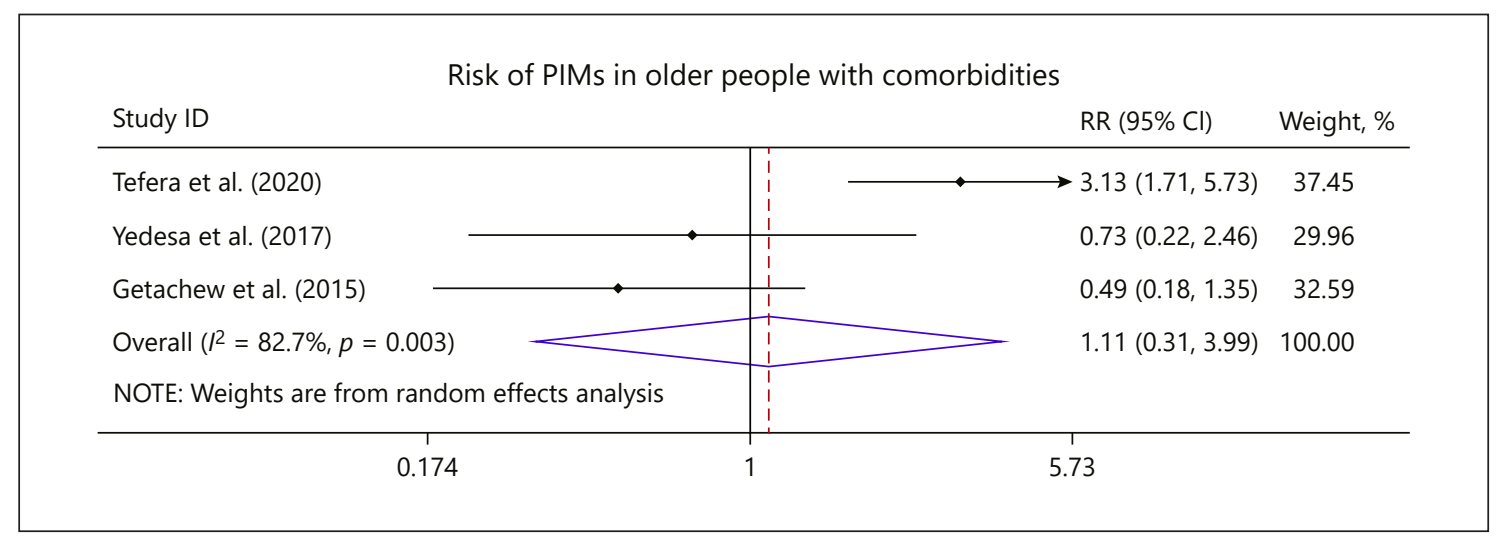

Fig. 5. PIMs in older patients with comorbidities $[31,33,36]$. PIMs, potentially inappropriate medications; CI, confidence interval; RR, relative risk.

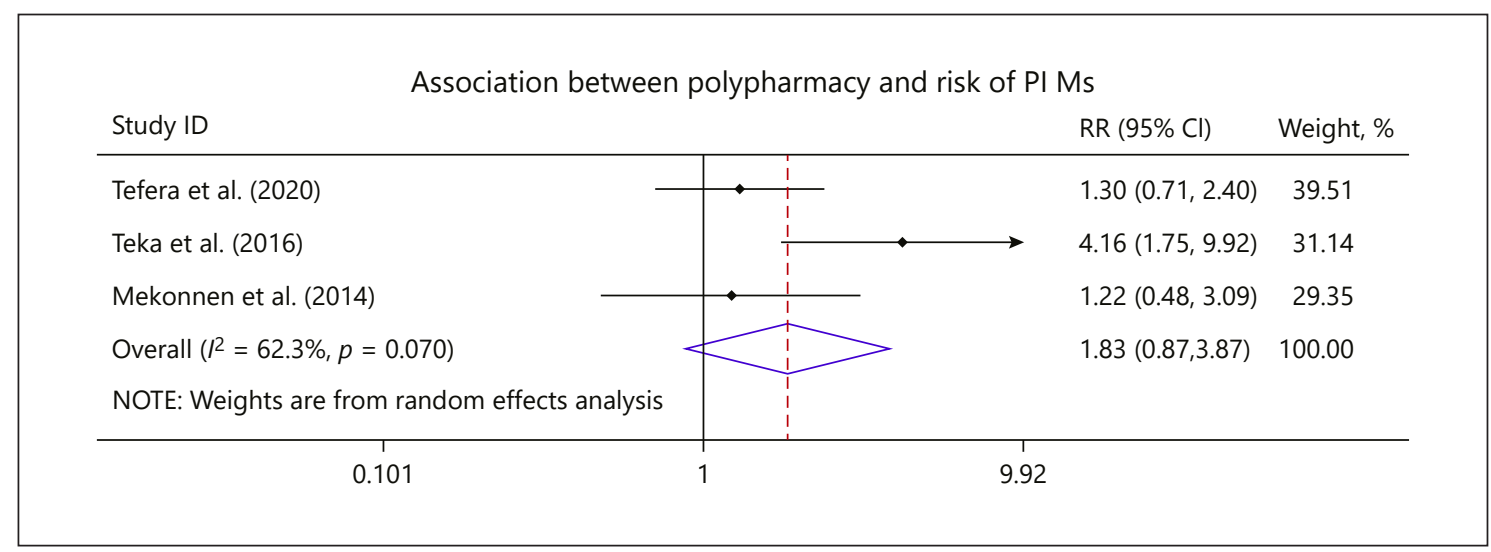

Fig. 6. Polypharmacy and risk of PIMs in the Ethiopia older population $[31,35,37]$. PIMs, potentially inappropriate medications; $\mathrm{CI}$, confidence interval; RR, relative risk.

studies that reported prevalence estimates, with $I^{2}$ statistics of $98.5 \%(p<0.001)$ (Fig. 3$)$.

\section{Factors Associated with Increased Risk of PIM Use} Older Age

A total of 7 studies reported the association of older age and risk of PIM use [31-33, 35-38]. The stratified meta-analysis revealed an increased risk of $26 \%$ PIM exposure in older adults (relative risk [RR]: 1.26, 95\% CI: $0.95-1.67, p<0.001$ ). Based on the patients' age-group, the population aged 65 years or older had a significantly higher risk of PIM use, which increased by $71 \%$ (RR: 1.71, $95 \%$ CI: $1.16-2.51, p<0.001)$ than the younger population. No significant reduction in the risk of PIM prescribing was confirmed for higher age categories ( $\geq 75$ years old and $\geq 80$ years old, R: 1.01, 95\% CI: 0.95-1.07, $p=$
0.116 and RR: $1.56,95 \%$ CI: $0.50-4.85, p<0.05$, respectively). There was a low heterogeneity among meta-analyzed studies $\left(I^{2}=29 \%\right.$; Fig. 4$)$.

\section{Gender}

Relevant data related to sex differences were extracted from 4 studies. The meta-analysis revealed that PIM use in the older population is not associated with gender differences (RR: 1.02, 95\% CI: 0.99-1.05, $p=0.712$ ) (online suppl. Fig. 1). There was no heterogeneity between the studies $\left(I^{2}=0.0 \%\right)$

\section{Polymorbidity}

Three studies demonstrated the relationship between polymorbidity and the risk of PIMs in the older population $[31,33,36]$. The combined analysis revealed an in- 
consistent association between the presence of polymorbidity and PIM use (RR: 1.11, 95\% CI: 0.31-3.99, $p=$ $0.05)$, and significant heterogeneity was noticed among studies $\left(I^{2}=82.7 \%\right.$; Fig. 5$)$.

\section{Polypharmacy}

Three studies investigated the association of polypharmacy with the risk of PIM exposure in the older population in Ethiopia [31, 35, 37]. The pooled effect estimate indicated no significant risk of prescribing PIMs (RR: 1.83 , 95\% CI: $0.87-3.87, p=0.036)$ in polypharmacy users. Heterogeneity between study results was moderate $\left(I^{2}\right.$ $=62.3 \% ; p=0.070)$ (Fig. 6).

\section{Publication Bias Assessment}

Funnel plots of standard error with logit RR supplemented by statistical tests confirmed that there is a source of publication bias on studies reporting polypharmacy in the older population in Ethiopia (Egger regression test [one-tailed], $p=0.001$; Begg correlation test [one-tailed], $p=0.015$ ) (online suppl. Fig. 2). Sensitivity analysis showed some of the individual studies contributed greatly to the heterogeneity of the estimates but did not showed significant differences beyond the 95\% CI limits, were identified, indicating that the omission of any one study did not significantly influence the overall meta-analysis results (online suppl. Fig. 3).

\section{Discussion}

Our study describes the first results of a comprehensive systematic literature review and meta-analysis summarizing the pooled prevalence of polypharmacy, PIM use, and risks of PIM prescribing in Ethiopia, a developing country. Based on our estimates, the overall prevalence of polypharmacy in the older population was 33\%, and PIM use $37 \%$, both affecting at least one in 3 older adults in the older population in Ethiopia. A recent metaanalysis based on primary care data reported the pooled prevalence of PIM use in older patients in middle-income countries as $23.2 \%$ and in high-income countries as $33.3 \%$ [14]. Our meta-analysis revealed a higher pooled prevalence of PIM use in Ethiopia (37\%) than in middle-income and high-income countries, even although financial resources in Ethiopia are insufficient and there is a well-known lack of necessary treatment strategies. This paradox of overtreatment with unnecessary medications and undertreatment with necessary medications was also reported by other studies in developed countries, particu- larly in the older age-group polypharmacy users with multiple comorbidities [42].

The current scientific literature demonstrates a rising trend of polypharmacy over the years [43]. A recent review by Davies et al. [9] reported several significant negative outcomes associated with polypharmacy, including mainly, adverse drug events, cognitive impairment, and disability. A previous study from Ethiopia described that around $75.3 \%$ of older adults who were exposed to polypharmacy had a $45 \%$ increased likelihood of hospital visits and were more likely to suffer from a severe impairment of quality of life by $91 \%$ [39]. Polypharmacy and hyperpolypharmacy (concomitant use of $\geq 10$ medications) in published studies are proxy indicators of PIM use and lead to adverse clinical outcomes [44, 45].

Nonsignificant findings between the risk of PIM use and polypharmacy or polymorbidity in our study also probably reflected the important differences between developed and developing countries. While in developing countries, principles of geriatric prescribing are probably not respected well enough in all cohorts of older patients (inadequate education of physicians and the health-care community), in developed countries, the risk of PIM use is substantially higher in polypharmacy users and younger and older adults (also because of a higher probability of being prescribed a PIM with an increasing number of medications in less frail older patients [46]). It is worth noting that current evidence-based guidelines do not provide adequate information on efficacy, safety, and dosing schedules for older patients suffering from polymorbidity and using multiple medications [47]. The cumulative impact of treatment recommendations often results in polypharmacy and an overwhelming medication burden. On the other hand, PIM use increases the risk of polypharmacy because frequent drug-related problems are usually inappropriately or underdiagnosed, and drugrelated complications are treated with other medications (such a phenomenon is called a "prescribing cascade" [48]). Equal risk of being prescribed a PIM in polypharmacy users and nonusers in our meta-analysis can therefore also be explained by the low awareness of physicians about the risk of PIMs in polypharmacy users and frequent prescribing of PIMs to all older patients (disregarding the level of polypharmacy, polymorbidity, and geriatric frailty).

There is a wealth of recent evidence on adverse outcomes associated with polypharmacy and PIM use, 2 major risk factors for inappropriate prescribing and negative outcomes in the older population. Data from the pooled analysis of 33 studies published by Xing et al. [13] in 2019 
highlighted that the risk of hospitalization was $27 \%$ and adverse drug events $44 \%$; however, no effect on mortality was documented. Salvi and colleagues' [49] review pointed out that polypharmacy is often associated with PIM use and was the main reason for drug-related hospitalization. It may significantly alter the pharmacokinetics and pharmacodynamics of many drugs, with an increased risk for older patients and patients with multiple chronic conditions [49]. Reducing inappropriate polypharmacy can be achieved particularly through educational and regulatory interventions. Optimizing geriatric care for older patients using polypharmacy as a valid and reliable measure of medication risk can help to reduce the use of PIMs, improve health outcomes, and substantially decrease health-care costs [47].

Increased PIMs with advancing age were shown in our meta-analysis in 7 studies [31-33, 35-38]. On the other hand, some studies from developed countries documented a lower risk of being prescribed a PIM in very old patients ( 80 years and older) due to higher awareness of physicians about the increased risks of PIMs in this age cohort because of higher rates of geriatric frailty and a higher risk of negative outcomes [46]. Although we noticed nearly a 2-fold increase in the risk of PIM use among the Ethiopian older population aged 65 or older, no significant reduction was found for higher age categories over the age of 75 and 85 years. Such findings may support our previous conclusion that in Ethiopia and may be also in other developing countries, older patients are extensively prescribed PIMs with disregard to age and other general risk factors or the significant role of higher selective mortality in these age cohorts. In contrast to some studies from developed countries, we also confirm no gender differences in PIM use, or significant association of PIM use with polymorbidity and polypharmacy.

Our results highlight the need to prioritize multipronged interventions in order to reduce the extensive prevalence of polypharmacy and PIM use and their potential iatrogenic harm in the Ethiopian population. Ethiopia is a country with limited health resources, substantial health-care problems, and early mortality of older adults $[25,27,33,37]$. More research is needed to allow other developing countries to estimate by meta-analyses the extent of polypharmacy and PIM use in order to make confident predictions that may help to improve rational geriatric prescribing in developing parts of the world. Some practical approaches, such as comprehensive medication reviews by clinical pharmacists, the possibility of interprofessional geriatric training, education of all

Polypharmacy and PIM Use in Ethiopia health-care professionals in main aspects of geriatric prescribing, and care etc., can motivate more clinicians to improve their understanding of optimal medication use and to improve rational drug prescribing in the older population.

\section{Strengths and Limitations}

This systematic review provided comprehensive, upto-date information and detailed evaluation of the prevalence of polypharmacy, PIM use, and its risk factors in Ethiopia. It is the first meta-analysis of this kind in the scientific literature published from a developing country. Estimates were summarized by percentages and RRs using random-effect meta-analyses to identify the prevalence and factors contributing to PIM exposure in the older population. However, the pooled analysis revealed inconsistent linkage of several factors associated with PIM use and showed high heterogeneity across several studies and so we were able to meta-analyze only some selected risks from selected studies. Definitions of polypharmacy vary in the included studies and did not use the common definition of polypharmacy (concurrent use of 5 or more prescription). Disparities in geographic location (rural vs. urban), socioeconomic status (poor vs. rich), level of education (uneducated vs. educated), and access to care may influence the polypharmacy and PIM use, thus warrants further investigation considering these factors. Funnel plots were asymmetric, and Egger and Begg's tests revealed significant publication bias, particularly in those studies that reported the prevalence of polypharmacy in the older population. Despite efforts to ensure the reliable results of the meta-analyses, our results (as do the results of all meta-analyses) depend on the quality of the included studies. It is worth noting that according to the NOS, the overall quality of the included studies in our sample was high (the mean score: 8.5/10). Also, some differences across meta-analyzed studies might contribute to differences in findings. First, all of the included studies were cross-sectional, mostly of a smaller sample size, but showed high methodological quality. Second, the included population represented sometimes specific cohorts of patients; for example, Abegaz et al. [32] studied patients with cardiovascular disorders, whereas Getachew et al. [36] studied hospitalized older patients on antithrombotic therapy. These 2 studies reported a higher prevalence of PIM use $[32,36]$ because hospitalized older patients in developing countries are prone to higher PIM exposure. Last, a few differences in the explicit criteria identifying PIMs may also contribute to some variations, as 3 studies used the 2012 Beers 
criteria [34, 35, 37], 2 applied a modified edition of the STOPP criteria (2015) [32,36], and one implemented the 2003 Beers criteria [38].

Our results cannot be generalizable to all low-income developing countries because of substantial differences in ethnic composition, prescribing patterns, culture, life circumstances, population health, and the quality of health care. More studies from other developing countries are needed to support our findings for the developing world.

\section{Conclusion}

This meta-analysis revealed a high prevalence of polypharmacy and PIM use in Ethiopia, a low-income developing sub-Saharan African country. With the population aging and rising trends of polypharmacy over the past decade, we identified a higher prevalence of PIM use in Ethiopia compared to high-income and middle-income countries. PIM use in older patients was independent of polymorbidity, gender and polypharmacy (the opposite of the results from developed countries), and highly prevalent in all cohorts of older patients. Therefore, clinical pharmacist interventions, educational, and regulatory measures are essential in order to reduce the high risk of inappropriate drug use in older patients in Ethiopia. Further studies are also needed to confirm that polypharmacy, PIM use, and risk factors in other developing countries follow similar patterns.

\section{Acknowledgements}

Research work of Assoc. Prof. D. Fialová has been supported by the project INOMED No. CZ.02.1.01/0.0/0.0/18_069/0010046, by the European Union's Horizon 2020 research and innovation program under the Marie Skłodowska-Curie grant agreement no 764632, PROGRESS Q42 program (KSKF-2 scientific group), and SVV 260417.

\section{Statement of Ethics}

The study protocol was registered in the PROSPERO (CRD42019141037).

\section{Conflict of Interest Statement}

The authors declare no conflict of interest.

\section{Funding Sources}

This research received no external funding.

\section{Author Contributions}

A.S.B. and D.F. have participated in all stages of this systematic literature review, from the design, extraction and interpretation of data, and final writing. A.S.B. and E.A.G. developed and conducted the search strategy. A.S.B. and E.A.G. extracted and analyzed the data. A.S.B. and D.F. conceived the study design. All authors participated in the writing and review of the final manuscript.

\section{References}

1 Garfinkel D, Mangin D. Feasibility study of a systematic approach for discontinuation of multiple medications in older adults: addressing polypharmacy. Arch Intern Med. 2010; 170(18):1648-54.

2 Scott IA, Hilmer SN, Reeve E, Potter K, Le Couteur D, Rigby D, et al. Reducing inappropriate polypharmacy: the process of deprescribing. JAMA Intern Med. 2015 May 1; 175(5):827-34

3 Guthrie B, Makubate B, Hernandez-Santiago $\mathrm{V}$, Dreischulte T. The rising tide of polypharmacy and drug-drug interactions: population database analysis 1995-2010. BMC Med. 2015;13(1):74.

4 Rieckert A, Reeves D, Altiner A, Drewelow E, Esmail A, Flamm M, et al. Use of an electronic decision support tool to reduce polypharmacy in elderly people with chronic diseases: cluster randomised controlled trial. BMJ. 2020;369:m1822.
5 Payne RA, Abel GA, Avery AJ, Mercer SW, Roland MO. Is polypharmacy always hazardous? A retrospective cohort analysis using linked electronic health records from primary and secondary care. Br J Clin Pharmacol. 2014 Jun;77(6):1073-82.

6 Kersten H, Hvidsten LT, Gløersen G, Wyller TB, Wang-Hansen MS. Clinical impact of potentially inappropriate medications during hospitalization of acutely ill older patients with multimorbidity. Scand J Prim Health Care. 2015 Oct 2;33(4):243-51.

7 Secora A, Alexander GC, Ballew SH, Coresh J, Grams ME. Kidney function, polypharmacy, and potentially inappropriate medication use in a community-based cohort of older adults. Drugs Aging. 2018 Aug 1;35(8):73550.
8 Porter B, Arthur A, Savva GM. How do potentially inappropriate medications and polypharmacy affect mortality in frail and non-frail cognitively impaired older adults? A cohort study. BMJ open. 2019 May 1;9(5):e026171.

9 Davies LE, Spiers G, Kingston A, Todd A, Adamson J, Hanratty B. Adverse outcomes of polypharmacy in older people: systematic review of reviews. J Am Med Dir Assoc. 2020 Feb 1;21(2):181-7.

10 Mohamed MR, Ramsdale E, Loh KP, Arastu A, Xu H, Obrecht S, et al. Associations of polypharmacy and inappropriate medications with adverse outcomes in older adults with cancer: a systematic review and metaanalysis. Oncologist. 2020 Jan;25(1):e94.

11 Thillainadesan J, Gnjidic D, Green S, Hilmer $\mathrm{SN}$. Impact of deprescribing interventions in older hospitalised patients on prescribing and clinical outcomes: a systematic review of randomised trials. Drugs Aging. 2018;35(4): 303-19. 
12 Muhlack DC, Hoppe LK, Weberpals J, Brenner H, Schöttker B. The association of potentially inappropriate medication at older age with cardiovascular events and overall mortality: a systematic review and meta-analysis of cohort studies. J Am Med Dir Assoc. 2017 Mar 1;18(3):211-20.

13 Xing XX, Zhu C, Liang HY, Wang K, Chu YQ, Zhao LB, et al. Associations between potentially inappropriate medications and adverse health outcomes in the elderly: a systematic review and meta-analysis. Ann Pharmacother. 2019 Oct;53(10):1005-19.

14 Liew TM, Lee CS, Goh SKL, Chang ZY. The prevalence and impact of potentially inappropriate prescribing among older persons in primary care settings: multilevel meta-analysis. Age Ageing. 2020;49(4):570-9.

15 Liew TM, Lee CS, Goh Shawn KL, Chang ZY. Potentially inappropriate prescribing among older persons: a meta-analysis of observational studies. Ann Fam Med. 2019 May 1;17(3): 257-66.

16 American Geriatrics Society 2015 Beers Criteria Update Expert Panel. American Geriatrics Society 2015 updated Beers criteria for potentially inappropriate medication use in older adults. J Am Geriatr Soc. 2015;63(11): 2227-46.

17 Topinkova E, Madlova P, Fialova D, Klan J. New evidence-based criteria for evaluating the appropriateness of drug regimen in seniors Criteria STOPP (Screening Tool of Older Person's Prescriptions) and START (Screening Tool to Alert Doctors to Right Treatment) [in Czech]. Vnitr Lek. 2008;54:1161-9.

18 Renom-Guiteras A, Meyer G, Thürmann PA. The EU(7)-PIM list: a list of potentially inappropriate medications for older people consented by experts from seven European countries. Eur J Clin Pharmacol. 2015 Jul;71(7): 861-75.

19 Pugh MJ, Hanlon JT, Zeber JE, Bierman A, Cornell J, Berlowitz DR. Assessing potentially inappropriate prescribing in the elderly Veterans Affairs population using the HEDIS 2006 quality measure. J Manag Care Pharm. 2006 Sept;12(7):537-45.

20 Lipton HL, Bird JA. Drug utilization review in ambulatory settings: state of the science and directions for outcomes research. Med Care. 1993;31(12):1069-82.

21 WHO. Global Health and Aging National Institute of Aging. National Institute of Health. US Department of Health and Human Services. 2011.

22 US Census Bureau Age: Census Brief. Available at: http://www.census.gov/prod/2001pubs/ c2kbr01-12.pdf Accessed 2020 Nov 2.

23 Tegegn HG, Tefera YG, Erku DA, Haile KT, Abebe TB, Chekol F, et al. Older patients' perception of deprescribing in resource-limited settings: a cross-sectional study in an Ethiopia university hospital. BMJ Open. 2018;8:e20590.

24 The World bank data. Available at: https:// data.worldbank.org/indicator/SP.POP.65UP. TO.ZS?locations=ET Accessed 2020 Nov 2.
25 Janakiraman B, Temesgen MH, Jember G, Gelaw AY, Gebremeskel BF, Ravichandran H, et al. Falls among community-dwelling older adults in Ethiopia; a preliminary cross-sectional study. PLoS One. 2019 Sept 10;14(9): e0221875.

26 Bekele GT, Allene MD, Getnet MG, Hunegnaw MT, Janakiraman B. Assessing falls risk and associated factors among urban community dwellers older adults in Gondar town, Northwest Ethiopia 2019: a cross sectional study. Int J Surg Open. 2020;24:177-84.

27 Mirkena Y, Reta MM, Haile K, Nassir Z, Sisay MM. Prevalence of depression and associated factors among older adults at ambo town, Oromia region, Ethiopia. BMC Psychiatry. 2018 Dec 1;18(1):338.

28 Shukuri A, Tewelde T, Shaweno T. Prevalence of old age hypertension and associated factors among older adults in rural Ethiopia. Integr Blood Press Control. 2019;12:23.

29 Morka ED, Yibekal BT, Tegegne MM. Eye care service utilization and associated factors among older adults in Hawassa city, South Ethiopia. PLoS One. 2020 Apr 16;15(4): e0231616.

30 Mekonnen GB, Beyna AT. Pharmacists' knowledge and practice of issues related to using psychotropic medication in elderly people in Ethiopia: a prospective cross-sectional study. BioMed Res Int. 2020;2020:7695692.

31 Tefera YG, Alemayehu M, Mekonnen GB. Prevalence and determinants of polypharmacy in cardiovascular patients attending outpatient clinic in Ethiopia University Hospital. PLoS One. 2020 Jun 1;15(6):e0234000. Erratum in: PLoS One. 2020 Jul 14;15(7):e0236328. PMID: 32479516; PMCID: PMC7263581.

32 Abegaz TM, Birru EM, Mekonnen GB. Potentially inappropriate prescribing in Ethiopian geriatric patients hospitalized with cardiovascular disorders using START/STOPP criteria. PLoS One. 2018 May 3;13(5):e0195949. PMID: 29723249; PMCID: PMC5933717.

33 Geresu GD, Yadesa TM, Abebe BA. Polypharmacy and the contributing factors among elderly patients in shashemene referral hospital, West Arsi, Oromia Region, Ethiopia. J Bioanal Biomed. 2017;9:277-82.

34 Sada O. Irrational use of medications among elderly patients in an Ethiopian referral hospital. Afr J Pharm Pharmacol. 2017;11(15): 191-4.

35 Teka F, Teklay G, Ayalew E, Kassa TT. Prevalence of potentially inappropriate medications in Ayder referral hospital, Tigray region, Northern Ethiopia: prospective study. J Drug Delivery Ther. 2016 Nov 14;6(6):16-21.

36 Getachew H, Bhagavathula AS, Abebe TB, Belachew SA. Inappropriate prescribing of antithrombotic therapy in Ethiopian elderly population using updated 2015 STOPP/START criteria: a cross-sectional study. Clin Interv Aging. 2016;11:819.

37 Mekonnen $A B$, Bhagavathula AS. Inappropriate medication use in the elderly population attending Gondar University hospital: a preliminary assessment. Int J Pharm Pharm Sci. 2014;65(74):910.

38 Teni FS, Gedif T. Prevalence and predictors of inappropriate medications prescribing among elderly outpatients at a University Hospital in Northwestern Ethiopia: a retrospective cross-sectional study. Ethiopia Pharma J. 2015;30(2):124-32.

39 Tegegn HG, Erku DA, Sebsibe G, Gizaw B, Seifu D, Tigabe M, et al. Medication-related quality of life among Ethiopian elderly patients with polypharmacy: a cross-sectional study in an Ethiopia university hospital. PLoS One. 2019 Mar 28;14(3):e0214191.

40 Moher D, Shamseer L, Clarke M, Ghersi D, Liberati A, Petticrew M, et al. Preferred reporting items for systematic review and metaanalysis protocols (PRISMA-P) 2015 statement. Syst Rev. 2015;4:1.

41 Newcastle- Ottawa: Quality assessment scale adapted for cross-sectional studies. Available at: https://wellcomeopenresearch. s3.amazonaws.com/supplementary/13880/ ea30a2fb-a15a-44a9-b35e-5f0914db80b3. docx Accessed 2020 Nov 1.

42 Cherubini A, Corsonello A, Lattanzio F. Underprescription of beneficial medicines in older people: causes, consequences and prevention. Drugs Aging. 2012 Jun 1;29(6):46375.

43 Wastesson JW, Morin L, Tan ECK, Johnell K An update on the clinical consequences of polypharmacy in older adults: a narrative review. Expert Opin Drug Saf. 2018 Dec;17(12): 1185-96.

44 Baldoni Ade O, Ayres LR, Martinez EZ, Dewulf Nde L, Dos Santos V, Pereira LR. Factors associated with potentially inappropriate medications use by the elderly according to Beers criteria 2003 and 2012. Int J Clin Pharm. 2014 Apr;36(2):316-24.

45 Nishtala PS, Salahudeen MS. Temporal trends in polypharmacy and hyperpolypharmacy in older New Zealanders over a 9-year period: 2005-2013. Gerontology. 2015;61(3):195202.

46 Fialová D, Topinková E, Gambassi G, FinneSoveri H, Jónsson PV, Carpenter I, et al. Potentially inappropriate medication use among elderly home care patients in Europe. JAMA. 2005 Mar 16;293(11):1348-58.

47 Fialová D, Laffon B, Laffon B, Marinković V, Tasić L, Doro P, et al. Medication use in older patients and age-blind approach: narrative literature review (insufficient evidence on the efficacy and safety of drugs in older age, frequent use of PIMs and polypharmacy, and underuse of highly beneficial nonpharmacological strategies). Eur J Clin Pharmacol. 2019 Apr;75(4):451-66.

48 Rochon PA, Gurwitz JH. Optimising drug treatment for elderly people: the prescribing cascade. BMJ. 1997 Oct 25;315(7115):1096-9.

49 Salvi F, Marchetti A, D’Angelo F, Boemi M, Lattanzio F, Cherubini A. Adverse drug events as a cause of hospitalization in older adults. Drug Saf. 2012 Jan 1;35(Suppl 1):29-45. 